\title{
Gender and the Risk of Falling: A Sociological Approach
}

\begin{abstract}
Background: The incidence and rates of falls among older people, including injurious falls, is a matter for much international concern. The risk of falling remains a major concern for older people since it increase with age, with those aged over 85 and over at greatest risk. However, research on sociological approaches that examine the ways in which older people with recurrent falls view their risk of falling and how they respond to it in relation to preventing future falls is limited.
\end{abstract}

Aim: This paper reports a grounded theory study which develops a sociological underpinning on how gender influences older people's perceptions of their risk of falling and their actions to prevent future falls.

Design: An exploratory design, with grounded theory analysis, was used. Data were collected in 2001 through in-depth interviews with 40 older people living in the South East England.

Findings: Two core categories emerged: gendered meanings of risk and gendered responsibility. The social construction of the meaning of the risk of falling and on their actions was gendered; older men and women had specific ways of talking about their 'risk', and identifying the risk factors for falling. Older men perceived themselves as 'responsible' and 'rational' individuals who expected to reduce their own risk of falling. 
Older women's expectation of themselves and of their peers explained their tendency to self blame and others for their falls. These perceptions consequently influenced the actions they took to prevent future falls.

Conclusion: Nurses and other healthcare professionals need to be aware of the gendered meanings attached to falling by older men and women. By including a critical sociological approach in falls prevention healthcare professionals would be able to develop meaningful and realistic falls prevention strategies involving older people and their family members.

Keywords: community, grounded theory, interview, nursing, older people, risk of falling. 


\section{SUMMARY}

\section{What is already known on this topic:}

- Most of the literature on falls among older people tends to have a biomedical approach which ignores the sociological perspective.

- Despite an increasing interest in using sociological approaches to examine how older people construct the meaning of the risk of falling, none has specifically examined the way in which gender influences the perceptions of the risk of falling.

\section{What this study adds:}

- Gender impacts on the social construction of the meaning of the risk of falling, and on the actions they took to prevent future falls.

- The portrayal by older men as responsible and rational reflects the gendered nature in their perceptions of falls prevention.

- Nurses and other healthcare professionals can enhance their understanding of older people with recurrent falls by accepting that there are gender differences in approaches to falls prevention. 


\section{INTRODUCTION}

The term 'risk' appears in much of the medical literature on falls among older people (Gillespie et al. 2001), particularly in relation to what the risk factors for falls are (Lord \& Dayhew 2001, Easterbrook et al. 2001), and the interventions taken in order to prevent falls (Day et al. 2002). Reviews of research on falls among older people (Askham et al. 1990, Lilley et al. 1995, Oliver et al. 2004) highlight the use of a biomedical and individualistic approach that tends to focus on "physiological and biological explanations' and excluding psychological or social factors influencing older people's experiences (Victor 1999, p. 9). However, little is known about the impact of gender on perceptions of the risk of falling. Green (1997) discusses how often risk was previously associated with both good and bad outcomes and more synonymous with chance. Concepts such as 'hazards', 'safety' and 'harm' are akin to the notion of 'risk' (Alaszewski 1998) and 'uncertainty' (Lupton 1999). Risk perception involves people's beliefs, attitudes, judgements and feelings, as well as the wider social or cultural values and dispositions that people adopt towards hazards (Pigeon et al. 1992).

Falls prevention policies are unlikely to be effective if the perspectives of older people are excluded because older people may need to be convinced of being at greater risk as they get older (Yardley \& Todd 2005). Reluctance by older people to take fall preventive measures poses a great challenge to health professionals in meeting the targets set in Standard 6 of the National Service Framework for Older People (Department of Health 2001). Furthermore, the transition to older age is associated with impending dependence and further decline (Kingston 2000) means that factors such as 
gender are often not recognised as having an influence in the perceptions of older people and their actions to prevent future falls.

The purpose of this article is to demonstrate how gendered perceptions of risk can influence the social construction of the meaning of the risk of falling among older people with recurrent falls and on their subsequent actions.

\section{BACKGROUND}

Key theoretical socio-cultural approaches to risk identified by Lupton (1999) include those put forward by Douglas (1966), Giddens (1991) and Beck (1992). According to Lupton (1999) risk is used in society to establish conceptual boundaries between the self and 'the Other'. This concept is often associated with Douglas' (1966) assertion that the body is used symbolically in discourses and practices that surround risk, reflecting society's anxieties about policing its boundaries (Adams 2001). Likewise, Giddens (1991) contended that through modernisations, contemporary Western society has become a 'risk society' and that the concern about risk not only occupies the public arena but also the domain of private lives. However, there is so little literature on older people's risk perceptions that it led Martin (1999) to draw on work relating to young people and sexual health to extend her understanding of the construction of risk by older people.

Similarly, from a life-course perspective Kingston (2000) drew on the analogy of a child's risk taking when he highlighted the conflict surrounding this concept. Citing an 
example of a child at a stage when he learns to walk, he pointed out that during this stage the child will fall 'reasonably consistently', a behaviour considered to be risk taking by the parents (p.224). As the risk outweighs the danger (superficial injuries) this behaviour is deemed acceptable and inevitable. The acceptability of risk alters at a later stage when an older person who takes risk and falls is perceived as 'foolhardy, with some apportioning of culpability, if not blame' (Kingston 2000, p.225). Some older people would choose to continue to live on their own rather than moving to a care home, despite knowing they have a greater risk of having falls if they remain in their own home (Wynne-Harley 1991). Older people may accept certain risks in order to avoid being patronised by professionals or younger relatives (Reed 1998). WynneHarley (1991) maintained that older people 'trade-off' certain risks; for example a woman may be more concerned about the risk of dying of hypothermia if she fell in an unheated bathroom than being electrocuted and falling over electrical wires. Similarly a woman continued to use her bicycle to alleviate her arthritis, which was a greater threat to her quality of life than the possibility of being involved in a road traffic accident. This could be applied to family caring situations where an older person and family carer might accept a few bruises and cuts resulting from the older person's fall as an acceptable trade-off for the maintenance of the older person's independence.

Little is known of gender and negotiations that exist in these caring situations where risk taking is concerned. If the fall experienced by the older relative has undesirable consequences, such as bone fractures, the older persons and their key family members 
might intervene to minimise the effects of the undesired event or to try to prevent future ones from happening.

The benefits of being perceived as an active, less dependent older person may outweigh the risk of falls and the restrictions imposed by self and others from activities such as shopping. Such impositions can be likened to the 'dread factor' indicated by Denscombe (1993) that influences perceptions in relation to the level of risk posed by a particular threat. For example, when a person is exposed to a risk frequently they tend to perceive the risk as less likely to happen than if exposed to the risk occasionally. In essence those who experienced more frequent falls might be dismissive of their risk of falling, which could result in them not being pro-active in taking measures to prevent future falls. Denscombe also highlighted that other factors influence the perceptions of risk including the perceived level of risk posed by a particular threat, personal experience, exposure to information, the sense of invulnerability, and the frequency with which the risk is encountered. Therefore, some older people trade-off certain risks, and this could influence their social meaning of falls, and their actions in preventing future falls.

The above discussion has illustrated how diverse risk perceptions can be and how limited the evidence is on how gender might impact on older people's perception of the risk of falling and on their actions to prevent future falls. It is difficult to uncover the often subtle and invisible processes in which these perceptions are constructed and to explore how gender construct health experiences. One way to uncover these processes 
and to bridge the gap in the literature is to draw on the evidence from my doctoral study that specifically examined the extent to which the meaning of the risk of falling is gendered.

\title{
THE STUDY
}

\begin{abstract}
Aim
The aim of the study was to achieve a deeper and broader understanding of older people with recurrent falls, and of their key family carers with specific emphasis on their social construction of the meaning and the risk of falling and their actions to prevent future falls. The part of the study reported here will explore from the perspective of older people the meaning of the risk of falling and the extent to which this is gendered (For reasons specified above).
\end{abstract}

\section{Methods}

For the required exploration, a qualitative design with grounded theory analysis, was used as it allows themes and concepts to emerge from an analysis of qualitative data collected (Ballinger \& Payne 2002, Strauss \& Corbin 1990, Williams 1999). The theoretical stance underlying the study is that of a symbolic interactionist approach which emphasizes that a social situation has meaning only in the way people define and interpret what is happening (Polgar \& Thomas 1995). Such meanings are 'derived from, or constructed through the social interactions that they have with others' (Blumer 1969, p.2). This process enables individuals to make sense of their experience (Strauss \& Corbin 1990). Since this study was concerned with exploring the social construction of the meaning of the risk of falling, a social constructive perspective was adopted to 
allow themes and concepts to emerge from the qualitative data (Green \& Thorogood 2004). The data were collected during 2001.

\section{Participants}

Older people living in community dwellings in South East England were approached. The inclusion criteria were: persons aged 65 and over who have had two or more falls in the past 12 months, and living alone either in their own home, in an annexe to their adult child's house, or in sheltered housing. A fall was defined as 'an event which results in a person coming inadvertently to rest on the ground' (Isaac 1987, p. 14-15). In this study, older people were asked if they have had any trips, slips or falls in the past 12 months, and if so, how many. Because of the difficulty in recruiting older men who met the sample criteria, four older men who were married and living with their wife, were included. All the married men were self-caring although one was physically frail. In total, twenty men and twenty women were interviewed, with their age ranging from 65-95 years and 65-94 years respectively. Eighteen of these lived in sheltered housing and the remainder in their own home. Due to the demographic profile in the sample sites all included participants were white British.

\section{Data collection}

Indepth interviews were conducted in participants' own home. Interviews consisted of exploratory questions that were grounded in theories relating to risk and fall prevention. Three pilot interviews were conducted to test the validity of the questions. An analysis was undertaken which indicated the need to modify the interview guide to explore further the impact of gender on the meaning of the risk of falling. An equal number of 
men and women were included to explore gender differences. The pilot interviews were included in the data. A total of forty participants were interviewed during 2001. Other sites were approached, resulting in recruitment of five older men from other organisations such as a club for disabled people, the Royal British Legion, and a retired members' branch of the Institution of Electronic Engineers.

\section{Ethical Considerations}

Following Ethics Committee approval potential participants were given written and verbal information about the study and had the opportunity to withdraw from the study at any time. Participants were assured that the only document containing their name was the consent form. For all subsequent records, data and documents the respondent was identified only by a code number or a pseudonym to preserve confidentiality.

\section{Data analysis}

The interviews lasted up to 90 minutes, were tape-recorded with consent and transcribed verbatim. Each transcript was read several times and analysed using a qualitative data analysis package, NUD*IST, which is ideal for handling large volumes of data (Searle 2000). This approach to the analysis drew heavily on the grounded theory perspective (Strauss \& Corbin 1990) which allows themes and concepts to emerge from the data and inform the theoretical framework (Charmaz 1990). Open and substantive coding ended with the emergence of a core category. Similarities and differences between men and women participants were compared, resulting in the codes being grouped into conceptually distinct areas such as meanings of risk, responsibilities, 
and types of actions by older people themselves in order to prevent future falls. The monthly research supervision meeting facilitated a reflection on the data and enabled discussion of the emerging themes arising from the analysis. These formal meetings provided an opportunity for the validity of the themes to be challenged and consensus reached by the supervision.

\section{FINDINGS}

\section{Gendered meanings of risk}

Older men and women had different perceptions of the risk of falling and these were reflected in their usage of other related terms to risk such as 'hazard', 'danger' or 'safe or safety'. Their perceived risks of falling were gleaned from what they thought made them more likely to fall than others of their age. Questions relating to their health and medical problems, medications, home environment, and their daily activities were also asked. The respondents were asked how confident they felt about walking indoors and outdoors, and what they thought they should or could have done to stop themselves from falling again. The word 'risk' was never directly mentioned by the interviewer..

This study identifies specific ways in which older men and women reported about 'risk', indicating that there was a gender difference in how risk was perceived. Not only were older people spontaneous in their accounts relating to the risk of falling, they also indicated that risk-taking was associated with personal responsibility and the responsibilities of others. More than half of the sample of men spontaneously 
articulated words like 'risk' and 'risky' compared to only one woman, as the following quotations illustrate:

I think I'm at risk of falling... I have low blood pressure and I suffer from giddy spells, especially if I get up too soon. (Mr S, 88 years)

To be honest with you, I'm a liability. I'm not safe to be alone... what with my angina and dizzy spells. (Mr T, 92 years)

I feel I am too risky to be going out on my own... I need my wife to be with me when we go to the clubs [day centre, etc]. I just don't feel safe in this sort of places without her around. (Mr H, 92 years)

If you're a sensible person, it's no good taking risk, I mean I don't even go to the dustbin. I'm not very good now carrying that sort of thing. (Mrs E, 84 years)

Their spontaneous use of words relating to risk implied that older men in particular had no difficulty in articulating words such as 'risk' or 'risky', 'liability', 'safe' and 'taking risk'; this challenged Martin's (1999 p.41) claim that risk perceptions were not clearly defined, and might be 'difficult to articulate'. The range of words articulated by older respondents in this study was consistent with Alaszewki's (1998) model of words related to risk, with the majority of men $(n=11)$ but only one woman using the term 'risk'. A greater diversity of words was used by older men than women, for example, 
'safe' or 'safety' was expressed by five women and nine men, while 'liability', 'danger', or 'hazard(ous)' were only articulated by older men and not by older women.

Older people perceive their risk of falling or the factors that might contribute to their falls as either 'intrinsic' or 'extrinsic' or both, supporting those identified by health professionals, among whom the consensus is that a combination of several factors contributes to a fall (Lord \& Dayhew 2001). Intrinsic refers to risks related to the physiological changes associated with ageing, as in the case of $\mathrm{Mr} \mathrm{S}$ and $\mathrm{Mr} \mathrm{T}$, while extrinsic risk refers to external factors such as their daily activities or the environment. In Mrs E's case, the extrinsic risk factor was emptying her rubbish into the dustbin and this was seen as putting her at risk of falling. Examples of the risk factors identified are as follows:

Uneven pavements or bad shoes. The road outside here is very bumpy, very uneven, and I am wary when I walk out of this house just in case I fall... My legs, they are not as good as they used to be, so they do sometimes just give way. They are just as likely to make me fall. (Mrs H, 92 years)

I think using the staircase is more likely to give me the feeling that I might fall. (Mrs C, 77 years)

You lose your balance very quickly, you have to be careful when you get up, you have to stand there a couple of minutes to get equilibrium or you tend to fall one way or the other. (Mr W, 78 years) 
No ragged carpets or anything like that. I don't think there are any things hazardous in here. I've kept my furniture to a minimum so that it is not cluttered in here. (Mr T, 92 years)

Generally, perceptions of their risk of falling were thought to influence what they do to prevent future falls. For example, uneven pavements and her weak legs might put Mrs $\mathrm{H}$ at risk of falling, and this caused her concern when she left her house. Arguably the type of environmental challenges that older persons choose to expose themselves to, or the extent of a person's risk taking behaviour would have an important impact upon their subsequent actions to prevent future falls. The types of perceived risk factors, intrinsic or extrinsic, could have an influence on the extent to which older people thought they had any control in order to reduce the risk. For example, extrinsic factors would be more likely to be considered as 'controllable'; a home modification environment, whereas an intrinsic factor like dizziness may be less controllable because of the physiological changes in the body.

Older people also reported medical and health problems as risk factors for falls, consistent with Stuck et al.'s (2000) study, which found that with advancing age, health factors featured more prominently as risk factors or causes of falls. However, in this study, over twice as many older men $(n=13)$ as older women $(n=5)$ identified extrinsic factors associated with the home and public environment as representing a risk to falling, more than twice as many men $(n=14)$ as women $(n=5)$ considered their daily activities contributed to their risk of falling. Further examination of the number of risk 
factors articulated by older people in relation to their likelihood of falling revealed a distinct gender difference, with more older women $(n=7)$ citing no risk factors, and older women reporting fewer risk factors. Interestingly, few cited age or their eye sight as risk factors; although nearly half $(n=18)$ of the respondents $(n=40)$ took four or more types of medications, none identified this as a risk factor.

\section{Gendered Responsibility}

An emergent theme from the data concerns older people's notion of gendered responsibility. This study draws on the work of Kemshall \& Pritchard (1997, p.10) who argued that risk-taking 'has to be balanced against exposing self, others or their property to unnecessary harms and dangers'. The authors advocated that the benefit of hindsight assisted people to put into context what their expectations of themselves and of others are, and decide which aspects were relevant or not. However, in this study such expectations were gendered, with most of the older men $(n=16)$ portraying themselves as 'responsible' and 'rational' individuals:

I don't deliberately put myself at risk you know. Certainly not at my age. (Mr T) What do you mean by not deliberately put yourself at risk? (Researcher) Oh anything that you shouldn't be doing if you know that's going to make you fall. Like if I know that getting up too soon will make me fall, then I jolly well make sure I mustn't do that. (Mr T, 92 years) 
Mr T's desire for his own independence and autonomy can be seen through his own deliberate and careful analysis of how he ought to get up slowly. This implied that the maintenance of independence and autonomy by older people influences the way they set limits and restrictions since reasonable and calculated risk-taking was an important aspect in the quality of the life of older people (Wynne-Harley 1991). This was also illustrated by Mr F's and Mr H's comments:

It's a matter of assessing your risk, and you start looking around the home environment and work out which might cause you a problem, or pose a danger really. I have installed this special BathKnight, which is brilliant, it takes away that problem of having to get out of the bath, and worrying about falling about in the bathroom. (Mr F, 75 years)

I don't feel safe to go up on the bus myself, I don't feel safe to go out on my own anymore. It's strange, I know I shouldn't because I can walk quite steadily with this frame now, but at the back of my mind, I still feel uneasy, just in case I should land on the ground again... If that happens, I should hate to be in hospital and then who knows, they might put me into a home. Now that's something I wouldn't like to be in. (Mr H, 92 years)

Like most men in this study, Mr F's and Mr H's exertion of personal control and decision making reflects the masculine identities of these men (Connell 1995, Charmaz 1995). The threat posed by the risk of falling may have led these men to examine how and why they had fallen. According to Gradman (1996), gender-appropriate attitudes such as 'instrumental orientation' (focus on getting the job done) and 'analytical orientation (relying on step-by-step logic) are often emphasised by older men' (p.107). 
In this study, it is argued that the analytical orientation guides these older men in their behaviour. The risk of falling is salient to older people who have had falls, but is articulated more explicitly by older men than women, which may impinge on how they differentially constrain their behaviour or risk-taking.

Like older men, some older women considered risk taking to mean restricting some activities, and thus exerting personal control. Nearly twice as many older men $(n=12)$ as women $(n=7)$ reported undertaking self-restricting actions, including not going out on their own, foregoing housework and house maintenance. These self-regulating activities are attempts to maintain their independence. The self-imposed restrictions of activities by older women were similar to those of older men, for example:

But I can't get up to clean my windows, I can't get up and change my curtains. If I did that, I probably would fall. Well, bending down and holding a heavy dish, I could topple over. (Mrs M, 73 years)

Now if you ask me to clean my windows... no way. It's too risky... If I leaned back too much, I would lose my balance, and bang, I would be on the floor. (Mr W, 78 years)

Even though Mrs M did not articulate the word 'risk' or other related terms, it is obvious that her concerns were about taking risks. Her personal limitation in undertaking certain tasks was seen as increasing her risk of falling. Similarly Mr W was not prepared to take the risk of cleaning his windows for fear of losing his balance and falling. 
Older women constructed their meaning of the risk of falling through their expectation of self and others:

A lady upstairs [in sheltered housing] goes round with a zimmer frame but you wouldn't think there was room in these houses... I have a friend who fell off a chair and broke her arm. She was stupid to go on the chair. (Mrs C, 77 years)

There's a lady here [in same sheltered housing], Mrs B, who keeps falling, always ends up in hospital. She lives downstairs. Do you know, she still gets about with her sticks, silly really. I think she shouldn't be walking about like that, she's bound to fall. No wonder she keeps falling. She should be in a wheelchair really. (Mrs D, 94 years)

The gendered nature in which risk was perceived is reflected in these women's criticism of other people's actions, which they considered as 'careless risks'. Such 'contempt' has been echoed by Green (1997) in an exploratory study of children's perceptions of how accidents happen who found that girls were critical of those who took careless risks. The moral expectation of others to restrict or avoid certain activities may impact on older people's willingness to take risks for fear of being perceived by others as 'stupid'. It was interesting that none of the twenty older men were critical of other people's risktaking behaviour. 
Older women also tended to attribute their own carelessness to falling, reflecting a willingness on their part to self-blame. None of the older men self blamed. Despite this, it is proposed that older women were less aware than older men of the risks that expose them to falling, contrary to the argument that women's notions of risk-taking are highly associated with assumptions about femininity, which are likely to depict 'the careful avoidance of danger and hazard as important' (Lupton 1999, p. 161). However, a counter-argument is that women's notions of risk-taking are reflected in their 'ongoing' activities, that is, they have always carried out these activities but do not articulate them as 'risk-taking behaviour'.

The familiarity of the older person's home environment may have also influenced the way risk has been constructed. Denscombe's (1993) notion of 'familiarity breeds contempt' offers a helpful explanation where people tend to underestimate risks that they face routinely compared with the risks they face occasionally, as illustrated by $\mathrm{Mr}$ $\mathrm{H}$, in this study:

Tripping over the mat or something. I am aware of this but I am taking the risk I know. I am just more careful about it when I am walking near this mat here. I know it is no good but it's been there to cover up the worn patch underneath. I reckon so long as I am careful it should be alright. (Mr H, 83 years)

Routinely exposed to familiar risk is commonly perceived by older people who regard loose rugs as hazardous but are especially careful around them, or use them to cover 
wires that would otherwise be a greater potential hazard (Sattin et al. 1998). This finding supports the work of Clemson et al. (1999) who found older people's understanding of environmental risks and their decision whether to curtail actions is related to their past experience or behaviour in a specific environment.

In summary, the perceptions of the risk of falling of older men and women were gendered. The use of terms such as risk, hazards, danger and safe/safety were varied; older men who have had falls tended to articulate these terms more spontaneously than older women. the use of terms such as risk, hazards, danger and safe/safety are varied, and that older men who have had falls tended to articulate these terms more spontaneously than older women. By analytically identifying factors that make them

more likely to fall than others, older men strived to portray themselves as 'rational individuals'. It could be argued that because of the stigmatising impact associated with falling, particularly in public places, older men were keener to 'sustain' their masculinity since their 'public' self was more likely to be threatened when they fall in public places.

\section{Study limitations}

A larger sample, with stratification (purposive) could provide a better representation of age range and generations, which could justify generational differences about falls. This could also target participants from different ethnic groups and cultures where differences within and between findings could occur. 
Although the data was collected five years ago, no studies have been published since then that explored the same specific questions. The perceptions of older people with recurrent falls remain valid and relevant to falls prevention.

\section{CONCLUSIONS}

Although this study was conducted in the United Kingdom, the findings have wider relevance for the care of older people, particularly in terms of risk perceptions, gender issues and care assessment. My study has shown that the gendered construction of the meaning of risk by older people shapes their perceptions of the risk of falling, and is reflected in older women's self blame and their criticism of those who took 'careless risk'. In contrast, none of the men blamed themselves or others for the falls they had experienced. It is argued that 'gendered responsibility' may hold that key to nurses and other health professionals' understanding of why older men and women might take different approaches to fall prevention such as the need by older men to exercise greater control and take responsibility by being pro-active

The findings of this study have implications for healthcare practice. Older men and women construct the meaning of the risk of falling differently and need to be involved in risk assessment by nurses and other health professionals. It is not easy for these professionals to recognise this as an important aspect to consider when planning care because older women differ from their male counterparts in articulating 'risk' and are more likely to blame themselves. The emphasis nurses and other health professionals put on identifying risk factors could place older women in a disadvantaged position 
where blame for their own carelessness is accepted as a natural reaction and they are not encouraged to explore further about what actually puts them at risk. It may be necessary for nurses and health professionals to spell out the risks that predispose older people to falling. In contrast, older men's portrayal of themselves as responsible individuals might result in minimising their own risk, without any further guidance or advice from health professionals. It appears that any strategy for falls should take into account the gendered nature of risk perceptions among older people. Further research is needed to explore the negotiations between nurses and older people with recurrent falls in falls prevention and management. This could include exploring differences in age, class and ethnicity.

\section{References}

Adams J. 1995 Risk. University College London Press, London..

Adams T. 2001 The social construction of risk by community psychiatric nurses and family carers for people with dementia. Health, Risk and Society, 3,307-319.

\footnotetext{
Alaszewski H. 1998 Health and welfare: managing risk in late modern society. In Risk, Health and Welfare (Alaszewski A. Harrision L. \& Manthorpe J. eds.), OU Press, Buckingham, UK. pp.127-154.
} 
Alaszewski A, Harrison L. \& Manthorpe J. (eds) 1998 Risk, Health and Welfare. OU Press, Buckingham, UK

Askham J. Glucksman E. Owens P. Swift C. Tinker A. \& Yu G. 1990 A review of Research on falls among Elderly People. Age Concern Institute of Gerontology, King's College, London.

Ballinger C. \& Payne S. 2002 The construction of the risk of falling among and by older people. Ageing and Society, 22, 305-324.

Beck U. 1992 Risk Society: Towards a New Modernity. Sage, London.

Blumer H. 1969 Symbolic Interactionism. Prentice-Hall, New York.

Charmaz K. 1990 'Discovering' chronic illness: using grounded theory. Social Science and Medicine. 30(11), 1161-1172.

Charmaz, K. (1995) Identity Dilemmas of Chronically Ill Men. In Men's Health and Illness- Gender, Power and the Body (Sabo,D. \& Gordon, D. eds.), .Sage, Thousand Oaks, CA. pp.266-291

Chater K. 1999 Risk and representation: older people and non-compliance. Nursing Inquiry 6: 132-138. 
Clemson L. Cusick A. \& Fozzards C. 1999 Managing risk and exerting control: determining follow through with falls prevention. Disability and Rehabilitation, 21(12): $531-541$.

Connell R.W. 1995 Masculinities. Polity Press, Oxford.

Day L. Fildes B. Gordon I. Fitzharris M. Flamer H. \& Lord S. 2002 Randomised factorial trial of falls prevention among older people living in their own home. British Medical Journal 325: 128.

Denscombe M. 1993 Personal Health and the social psychology of risk taking. Health Education Research 8(4): 505-517.

Department of Health 2001 National Service Framework for Older People. Department of Health, London.

Douglas M. 1966 Purity and Danager: an Analysis of Concepts of Pollution and Taboo. Routledge and Kegan Paul, London.

Easterbrook L. Horton K. Arber S. \& Davidson K. 2001 International Review of Interventions in Falls among Older People. Department of Trade and Industry/Health Development Agency, London. 
Giddens A. 1991 Modernity and Self-Identity. Polity Press, Oxford.

Gillespie L.D. Gillespie W.J. Robertson M.C. Lamb S.E. Cumming R.G. \& Rowe B.H. 2001 Interventions for preventing falls in elderly people (Cochrane Review). The Cochrane Library, Issue 3. Update Software, London.

Gradman T. 1994 Masculine Identity from work to retirement. In Older Men's Lives (Thompson, E. H. ed.), Sage, London. pp.104-121.

Green J. 1997 Risk and the construction of social identity: children's talk about accidents. Sociology of Health and Illness 19(4): 457-479.

Green J. \& Thorogood N. 2004 Qualitative methods for Health Research. Sage, London.

Kemshall H. \& Pritchard J. (eds) 1997 Good Practice in Risk Assessment and Management, 2. Protection, Rights and Responsibilities. Jessica Kingsley, London. pp.80-102.

Kingston P. 2000 Falls in Later Life: Status Passage and Preferred Identities as a New Orientation. Health 4(2): 216-233 
Lilley J.M. Arie T. \& Chilvers C.E.D. 1995 Special Review: Accidents involving older people: A review of the literature. Age and Ageing 24(4), 346-65.

Lord S. \& Dayhew, T. 2001 Visual risk factors for falls in older people. Journal of the American Geriatrics Society 49, 676-677.

Lupton D. 1999 Risk. Routledge, London.

Manthorpe J.\& Alaszewski A, 2000 Service users, informed carers and risk. In Managing Risk in Community Care, (Alaszewski A. Alaszewski H. Ayer S \& Manthorpe J. eds.), Bailliere Tindall, Edinburgh and London. pp. 47-70.

Martin C. 1999 The Construction of the Risks of Falling in Older People: Lay and Professional Perspectives. Scottish Health Feedback, Scotland, UK.

Mason J. 1996 Qualitative Researching. Sage, London.

Oliver D, Daly F, Martin F, \& McMurdo ET 2004 Risk factors and risk assessment tools for falls in hospital in-patients: a systematic review. Age and Ageing 33,122-130.

Pidgeon N. Hood C. Jones D. Turner B. \& Gibson R. 1992 Risk Perception. In Risk: Analysis, Perception and Management (Report of a Royal Society Study Group), The Royal Society, London. pp. 89-134. 
Polgar S. \& Thomas S.A. 1995 Introduction to Research in the Health Sciences. $3^{\text {rd }}$ Edition. Churchill Livingstone, London.

Reed J. 1998 Care and protection for older people. In Risk, Health and Health Care: A Qualitative Approach (Heyman, B. ed.), Edward Arnold, London. pp. 241-51.

Sattin R.W. Rodriguez J. Devito C. \& Wingo. P 1998 Home environmental hazards and the risk of fall injury events among community-dwelling older people: Study to assess falls among the elderly (SAFE) Group. Journal of American Geriatric Society 46, 669676.

Searle C. 2000 Using Computers to analyse qualitative data. In Doing Qualitative Research: A Practical Handbook (Silverman, D. ed.),. Sage, London. pp. 154-172.

Strauss A. \& Corbin J. 1990 Basics of Qualitative Research: Grounded Theory Procedures and Techniques. Sage, Newbury Park, California.

Stuck A. Egger M. Minder CE, Illiffe S. \& Beck JC. 2000 Preventive home visits to elderly people in the community: further research is needed. British Medical Journal 321, 513.

Victor C. 1999 What is old age? In Nursing Older People, 3rd edn (Redfern S. \& Ross F. eds.), Churchill Livingstone, Edinburgh, London.. pp.3-17. 
Wynne-Harley D. 1991 Living Dangerously: Risk taking, Safety and Older People. Centre for Policy on Ageing, London.

Yardley L. \& Todd C. 2005 Encouraging Positive Attitudes to Falls Prevention in Later Life. A Report for Help the Aged. Feb. London. 